\section{Successful management of acute kidney injury in severe acute pancreatitis with intra-abdominal hypertension using peritoneal dialysis}

Sir,

This letter is written to emphasize the edge of acute peritoneal dialysis (APD) over hemodialysis in the management of acute kidney injury (AKI) in severe acute pancreatitis (SAP) with intra-abdominal hypertension (IAH) through a case we encountered recently.

The 35-year-old chronic alcoholic male, presented with acute abdominal pain and repeated episodes of nonbilious vomiting, following an alcohol binge. He was diagnosed to have hemorrhagic SAP by clinical features, lab investigations and imaging. He developed severe AKI with anuria within $48 \mathrm{~h}$ of admission and was initiated on hemodialysis. Hypotension was not recorded throughout the course of illness. He developed tense ascites by the end of $1^{\text {st }}$ week and was deteriorating with persistent systemic inflammatory response syndrome, and anuria despite hemodialysis and paracentesis. His intra-abdominal pressure (IAP) was recorded to be $26 \mathrm{mmHg}$.

He was shifted to APD using rigid catheter mainly to decompress the abdomen gradually using tidal exchanges as well as based on the fact that peritoneal dialysis helps in the removal of bioactive substances presumed to be responsible for systemic inflammation associated with acute pancreatitis. ${ }^{[1]} \mathrm{IAH}$ is known to reduce the blood supply to the abdominal organs, including the kidneys and is a common cause of AKI. ${ }^{[2]}$ Exact incidence of IAH is not clearly known as IAP is not measured routinely. IAP $>15 \mathrm{mmHg}$ is associated with higher mortality. ${ }^{[3]}$ Endotoxins and reactive oxygen species also play an important role in the pathophysiology of alkaline phosphatase and AKI. ${ }^{[4]}$

Percutaneous drainage is the preferred initial therapy in the presence of ascites or pseudocyst. Decompressive laparotomy is the most effective way of relieving IAP. In stable patients with infected necrosis, surgical, radiologic, and/or endoscopic drainage should be delayed, preferably for 4 weeks, to allow the development of a wall around the necrosis. ${ }^{[5]}$ We suggest APD as the preferred modality of renal replacement therapy in patients with SAP with AKI and IAH.

\section{Jaya Prakash Nath, Jacob George, Mohan Das, Noble Gracious, Sajeev Kumar, N. S. Vineetha Department of Nephrology, Government Medical College, Trivandrum,} Kerala, India

Correspondence: Dr. Jaya Prakash Nath, Department of Nephrology, Government Medical College, Medical College PO, Trivandrum - 695 011, Kerala, India. E-mail: jpnath2008@gamil.com

\section{References}

1. Ansari N. Peritoneal dialysis in renal replacement therapy for patients with acute kidney injury. Int J Nephrol 2011;2011:739794.

2. Li H, Qian Z, Liu Z, Liu X, Han X, Kang H. Risk factors and outcome of acute renal failure in patients with severe acute pancreatitis. J Crit Care 2010;25:225-9

3. De Waele JJ, Hoste E, Blot SI, Decruyenaere J, Colardyn F. Intra-abdominal hypertension in patients with severe acute pancreatitis. Crit Care 2005;9:R452-7.

4. Petejova N, Martinek A. Acute kidney injury following acute pancreatitis: A review. Biomed Pap Med Fac Univ Palacky Olomouc Czech Repub 2013;157:105-13.

5. Tenner S, Baillie J, DeWitt J, Vege SS, American College of Gastroenterology. American College of Gastroenterology guideline: Management of acute pancreatitis. Am J Gastroenterol 2013;108:1400-15.

\begin{tabular}{|l|l|}
\hline \multicolumn{2}{|c|}{ Access this article online } \\
\hline Quick Response Code: & Website: \\
& www.ijccm.org \\
\cline { 2 - 3 } & \\
\hline
\end{tabular}

